\title{
Empathy score among medical students in Mashhad, Iran: study of the Jefferson Scale of Physician Empathy
}

Amir Akhavan Rezayat ${ }^{1}$, Najmeh Shahini ${ }^{2,3}$, Hamid Toofani Asl ${ }^{4}$, Lida Jarahi ${ }^{5}$, Fatemeh Behdani ${ }^{6}$, Seyed Reza Habibzadeh Shojaei ${ }^{7}$, Javad Sadeghi Allah Abadi ${ }^{8}$

\footnotetext{
${ }^{1}$ M.D, Mashhad University of Medical Sciences, Mashhad, Iran

${ }^{2}$ M.D. of Psychiatry, Psychiatry and Behavioral Sciences Research Center،Mashhad University of Medical Sciences, Mashhad, Iran

${ }^{3}$ M.D. of Psychiatry, Golestan Psychiatry Research Center, Golestan University of Medical Sciences, Gorgan, Iran

${ }^{4}$ MD, of Psychiatry, Assistant Professor, Department of Psychiatry, Mashhad University of Medical Sciences, Mashhad, Iran

${ }^{5}$ MD, MPH, of Community Medicine, Associate Professor, Department of Community Medicine, Faculty of Medicine, Mashhad University of Medical Sciences, Mashhad, Iran

${ }^{6}$ M.D. of Psychiatry, Professor of Psychiatry, Psychiatry and Behavioral Sciences Research Center, Ibn-e-Sina Hospital, Mashhad University of Medical Sciences, Mashhad, Iran

${ }^{7}$ Student Research Committee, Department of Orthopedics, Faculty of Medicine, Mashhad University of Medical Sciences, Mashhad, Iran

${ }^{8}$ Eye Research Center, Khatam-AL-Anbia Eye Hospital, Mashhad University of Medical Sciences, Mashhad, Iran
}

Type of article: Original

\begin{abstract}
Background: Empathy is one of the essential components of physician-patient relationship that has a significant effect on treatment outcomes.

Objective: The aim of this study was to assess the empathy score among medical students in Mashhad, Iran.

Methods: In this cross-sectional study in 2015, 624 medical students at Mashhad University of Medical Science (Iran) completed the Jefferson Scale of Physician Empathy (JSPE). Data were analyzed by SPSS ver. 16, using independent-samples t-test, Chi-square, MANOVA, Spearman correlation, and Confirmatory factor analysis.

Results: Of the $38.4 \%$ males and $65 \%$ females who participated in this study, the mean score of JSPE in the sample was $103.67( \pm 15.34)$ which was higher in women than in men. Also, the mean scores for each of the three factors of the scale were calculated. The total empathy score, compassionate care, and taking perspectives among different age groups were significant $(\mathrm{p}=0.000)$. Furthermore, students having high interest in their field were more empathic $(\mathrm{p}=0.008)$. Empathy of interns in relation to three areas of basic sciences (the first year, the second year and the first half of the third year), physiopathology (the second half of the third year, and the fourth year), and clinical trainings (the fifth year, and the first half of the sixth year), experienced significant reduction $(\mathrm{p} \leq 0.001)$.

Conclusions: This study showed that empathy was higher in women in their first medical year and who were of younger age. The overall rate of empathy in the basic sciences period was more than that in the clinical period. Therefore, the initial exposure to clinical education, especially patient education and empathy, has a very prominent effect on the ability of medical students.
\end{abstract}

Keywords: Empathy, Medical students, Jefferson scale of Physician Empathy

\section{Introduction}

Empathy is a very important factor, and is one of the first communication factors in the relationship between physician and patient (1-10). It is also considered as a proprietary factor in the medical profession (11). It can be

\section{Corresponding author:}

Seyed Reza Habibzadeh Shojaei, Student Research Committee, Department of Orthopedics, Faculty of Medicine, Mashhad University of Medical Sciences, Mashhad, Iran.

Tel.: +98.9153180030, Fax: +98.5138762170, Email: Shojaeir931@mums.ac.ir

Received: August 31, 2016, Accepted: December 27, 2017, Published: July 2018

iThenticate screening: November 28, 2017, English editing: June 18, 2018, Quality control: June 18, 2018

Ethics approval: 911016

(C) 2018 The Authors. This is an open access article under the terms of the Creative Commons Attribution-NonCommercialNoDerivs License, which permits use and distribution in any medium, provided the original work is properly cited, the use is non-commercial and no modifications or adaptations are made. 
defined as a cognitive attitude to understanding the suffering and pain of a patient and the ability to understand and help him (12-15). Empathy is a broad concept that has many meanings, due to different theories and attitudes (1618). A number of studies have suggested that empathy in a physician-patient relationship improves patient satisfaction $(16,19)$, increases indulgency $(20)$, increases the doctor's ability to diagnose and treat $(20)$, reduces the risk of medical malpractice (21) and improves clinical outcomes $(9,13)$. Jefferson created a tool to measure the level of empathy among health professionals (HP version) and students (S-version) (22), which is currently translated into 38 languages including Persian (2). According to the previous studies, the construct validity, criterion-related validity, predictive validity, internal consistency, and test-retest reliability of the JSE have been approved (17). This tool has been expanded by Hojat et al. (17). This scale is also validated in Iran (2). Jefferson's empathy assess ment tool includes three factors, which include perspective taking, compassionate care, and ability understand things from the perspective of the patient (14). These three factors have been used in various studies. However, no studies yet exist on the examination of the JSPE scale among medical students. This study has been conducted to evaluate empathy among medical students. The study aimed to measure psychometric characteristics of the JSPE scale among medical students in Mashhad, Iran, from March to September 2015.

\section{Material and Methods}

\subsection{Research design and participants}

This cross-sectional study was conducted from March to September 2015. To determine the sample size, preliminary data were obtained. The quantitative dependent variables were determined according to the study of Hojat et al. (1). Inclusion criterion was being a medical student, and the following were set as the exclusion criteria:

1) Aged older than 30 years

2) Having a history of drug or alcohol abuse or personality disorder.

3) Having a history of psychiatric problems.

4) Having no written informed consent.

\subsection{Instrument}

JSPE-Health Professional Version is a tool for evaluating physician and patient communication (9). It is a selfreporting tool and contains 20 questions (from strongly disagree to strongly agree). The Persian version has previously been used by general practitioners and assistants (2).

\subsection{Data collection}

The Iranian student version of the JPSE-S was distributed to a number of medical students of Mashhad University of Medical Sciences (IRAN) in September 2015. Similar studies were used to determine the sample size (3). A total of 700 volunteers completed the JSPE-S. Participants of this study were residents from 5 large governmental hospitals in Mashhad (Iran) and they were given 20 minutes to complete the questionnaire themselves. To cover almost all residents, three different fields of residency were selected. To investigate the underlying components of the Jefferson Scale of Physician Empathy, data were subjected to principal component analysis by using Varimax rotation method. The researchers selected students from different years with convenient sampling. A total of 665 completed questionnaires were received; however, only 624 of these questionnaires were analyzed in the study. Forty-one questionnaires were omitted due to incorrect scoring.

\subsection{Ethics of research}

The protocol was approved by the Ethical Committee of Mashhad University of Medical Sciences (Ref. no.: 911016). The study was performed in accordance with the Declaration of Helsinki and subsequent revisions. Participants voluntarily completed the questionnaire and written informed consents were obtained from students before entering the study.

\subsection{Statistical analysis}

The data were analyzed using descriptive statistics; including tests for assessing the normality of the data, independent-samples t-test, Chi-square, MANOVA, Spearman correlation, and Confirmatory factor analysis. MANOVA was used to assess the effect of gender on scores of JSPE and its three factors. The data were analyzed by SPSS-16 (SPSS Inc., Chicago, Illinois, USA). P-values of less than 0.05 were significance level.

\section{Results}

In this study, 640 questionnaires were completed, which were mostly by women. Of these, $33 \%$ were in the field of basic sciences, $13.2 \%$ were physiopathology (second half of the third year, and fourth year), $31.4 \%$ were clinical 
trainings and $22.1 \%$ were interns (Table 1). Mean score of JSPE in the sample was $103.67( \pm 15.34)$. The mean scores for each of the three factors of the scale were also calculated. The mean scores for perspective taking were $51.25( \pm 10.53)$ and compassionate care $43.52( \pm 7.02)$, while ability to understand views from the perspective of the patient had a mean score of $8.87( \pm 2.79)$. Subsequent tests of between-subjects effects showed that the female group scored significantly higher on compassionate care with $\mathrm{p}=0.003$ (95\% CI: -2.23 to -0.22 ), but the differences were not significant on ability to understand views from the perspective of the patient and perspective taking. The study found an inverse significant relationship between the students' age and mean empathy score, perspective taking, and compassionate care. Table 2 shows the correlation between empathy and factors with independent variables. Post hoc tests to determine differences between groups were carried out and the results are shown in Table 3.

Table 1. Demographics of the participants in the study

\begin{tabular}{|l|l|l|}
\hline Variable & $\mathrm{n}(\%)$ \\
\hline \multirow{3}{*}{ Sex } & Male & $248(40)$ \\
\cline { 2 - 3 } & Female & $376(60)$ \\
\hline \multirow{3}{*}{ Age (year) } & $<22$ & $321(51.4)$ \\
\cline { 2 - 3 } & $22-24$ & $167(26.7)$ \\
\cline { 2 - 3 } & $\geq 25$ & $136(21.7)$ \\
\hline Level of education & Basic sciences & $206(33.0)$ \\
\cline { 2 - 3 } & Physiopathology & $84(13.2)$ \\
\cline { 2 - 3 } & Clinical trainings & $196(31.4)$ \\
\cline { 2 - 3 } & Interns & $138(22.1)$ \\
\hline
\end{tabular}

Table 2. Correlation between the empathy and factors with independent variable

\begin{tabular}{|l|l|l|l|l|}
\hline Variable & $\begin{array}{l}\text { Mean Empathy } \\
\text { Score }\end{array}$ & $\begin{array}{l}\text { Perspective } \\
\text { taking }\end{array}$ & $\begin{array}{l}\text { Compassionate } \\
\text { care }\end{array}$ & $\begin{array}{l}\text { ability to understand } \\
\text { views from the } \\
\text { perspective of the patient }\end{array}$ \\
\hline Sex & 0.178 & 0.922 & 0.003 & 0.661 \\
\hline Age & 0.006 & 0.000 & 0.005 & 0.309 \\
\hline Interest in the field & 0.087 & 0.008 & 0.820 & 0.648 \\
\hline Level of education & 0.015 & 0.000 & 0.006 & 0.928 \\
\hline
\end{tabular}

Table 3. Correlation between the empathy factors with age groups

\begin{tabular}{|c|c|c|c|c|c|}
\hline \multirow{2}{*}{ Variable } & \multirow[t]{2}{*}{ (I) age } & \multirow[t]{2}{*}{ (J) age } & \multirow[t]{2}{*}{ Sig. } & \multicolumn{2}{|l|}{$95 \% \mathrm{CI}$} \\
\hline & & & & Lower Bound & Upper Bound \\
\hline \multirow[t]{6}{*}{ Compassionate care } & \multirow[t]{2}{*}{$<22$} & $22-24$ & 0.881 & -1.1149 & 1.9649 \\
\hline & & $25-27$ & 0.030 & .1772 & 4.5353 \\
\hline & \multirow[t]{2}{*}{$22-24$} & $<22$ & 0.881 & -1.9649 & 1.1149 \\
\hline & & $25-27$ & 0.131 & -.3819 & 4.2444 \\
\hline & \multirow[t]{2}{*}{$25-27$} & $<22$ & 0.030 & -4.5353 & -.1772 \\
\hline & & $22-24$ & 0.131 & -4.2444 & .3819 \\
\hline \multirow[t]{6}{*}{ Perspecting taking } & \multirow[t]{2}{*}{$<22$} & $22-24$ & 0.000 & 2.3477 & 6.9460 \\
\hline & & $25-27$ & 0.000 & 7.7621 & 14.2540 \\
\hline & \multirow[t]{2}{*}{$22-24$} & $<22$ & 0.000 & -6.9460 & -2.3477 \\
\hline & & $25-27$ & 0.000 & 2.6828 & 10.0396 \\
\hline & \multirow[t]{2}{*}{$25-27$} & $<22$ & 0.000 & -14.2540 & -7.7621 \\
\hline & & $22-24$ & 0.000 & -10.0396 & -2.6828 \\
\hline \multirow[t]{6}{*}{ Total Empathy } & \multirow[t]{2}{*}{$<22$} & $22-24$ & 0.004 & 1.1889 & 7.9829 \\
\hline & & $25-27$ & 0.000 & 9.1989 & 18.0086 \\
\hline & \multirow[t]{2}{*}{$22-24$} & $<22$ & 0.004 & $\begin{array}{l}-7.9829 \\
\end{array}$ & -1.1889 \\
\hline & & $25-27$ & 0.000 & 4.1180 & 13.9178 \\
\hline & \multirow[t]{2}{*}{$25-27$} & $<22$ & 0.000 & -18.0086 & -9.1989 \\
\hline & & $22-24$ & 0.000 & -13.9178 & -4.1180 \\
\hline
\end{tabular}

* The mean difference is significant at the .05 level.

The JSPE mean score was also compared in the following four groups of students: 1) students on their basic sciences studies (the first 2.5 years of medical program), 2) students on their physiopathology studies (from year 2.5 of their medical program till the end of year 4), 3) students on their clinical trainings (from year 5 to year 6.5 of their 
medical program), and 4) interns (on their last 1.5 years of medical program). The difference in various education levels showed that the total score on the intern empathy towards three areas of basic sciences were significantly reduced $(\mathrm{p}=0.000)$. When divided into two groups of basic science and clinical level, the results showed that the total score of empathy and the domain, perspective taking, and compassionate care were significantly different between the two groups (Table 4). Construct validity of the empathy scale showed that three meaningful factors emerged.

Table 4. Comparison of the total score of empathy and domains in basic science and clinical level

\begin{tabular}{|l|l|l|l|}
\hline Variable & Basic science & Clinical level & $\mathrm{p}$-value \\
\hline Total empathy score & $107.32 \pm 13.5$ & $97.91 \pm 16.2$ & $\leq 0.001$ \\
\hline Perspective taking & $54.55 \pm 7.76$ & $46.08 \pm 12.11$ & $\leq 0.001$ \\
\hline Compassionate care & $43.95 \pm 6.8$ & $42.83 \pm 7.2$ & 0.006 \\
\hline ability to understand views from the perspective of the patient & $8.83 \pm 2.7$ & $8.9 \pm 2.8$ & 0.808 \\
\hline
\end{tabular}

\section{Discussion}

This study examined the empathy score in medical students. The mean empathy score of this study (mean=103.67) was similar to the scores of Japanese (mean=104.3), Kuwaiti (mean=104.6) and Iranian (mean=105.1), and was lower than the scores of Chinese (mean=109.60) and Iranian medical students (mean=110.41) $(25,26)$. It may be due to differences in culture, ethnicity, race, religious beliefs and training systems. The average score of empathy in women was higher than in men. This is similar to other studies (26-30). Also, in dental students, it was shown that females scored significantly higher on the JSPE than males (30-32). Women showed more emotional perception in physician and patient relationships. (25). Also, several studies have suggested that female physicians (2) and female medical students $(1,22)$ gain a higher score of empathy and show a more positive attitude toward empathy with patients. The present study also showed similar results in which the empathy score was significantly higher in women. On the other hand, a few studies have shown no gender difference in empathy and few studies have suggested that there is no gender difference. In the present study, there was a significant difference only in the compassionate care factor; while in the study of van Ryn et al., in both domains, perspective taking and compassionate care were differences (33). Only in the study of Prabhu et al. was the mean empathy score of male students greater than female students (34). In this study, among different ages, empathy decreased with increasing age, and this was similar with the study of Khademalhosseini et al. (30). But in the study of Deliang Wen, there were no significant differences in the age groups. Statistical difference existed in empathy scores in different levels of education. This indicated that level of empathy declined in clinical level, followed by an increase in empathy scores in basic science, which is similar to those of Chinese (26), Japanese (22) Korean (35) Portuguese (36) and Kuwaiti (24) medical students, but different from American $(37,38)$ medical students. In this study, it was found that empathy score among medical students decreased when their educational years increased. The point of concern is that medical students should be educated in a way that they learn both scientific concepts of medicine and communicate with patients, and also learn how to empathize with them. Medical students must learn how to treat patients, not just to treat their diseases $(30,39)$. A cohort study conducted on internal residency students indicated that the amount of empathy with patients was much higher in the first year as compared to the last year of specialty (40). Regarding the study limitations, this study was cross-sectional in nature; so, a prospective study was needed to follow students. Also, larger study populations covering different medical colleges were needed to validate the results of this study.

\section{Conclusions}

This study shows significant differences in total empathy score. The overall rate of empathy in the basic sciences period was more than that of the clinical period. Therefore, early exposure to clinical training helps to enhance the empathy of medical students.

\section{Acknowledgments:}

This study was funded by Mashhad University of Medical Sciences, Mashhad, Iran (grant number: 911016). The authors would like to thank the Psychiatry and Behavioral Sciences Research Center, Ibn-e-Sina Hospital, Mashhad University of Medical Science. The voluntary participation and cooperation of medical students in this study is highly appreciated.

\section{Conflict of Interest:}

There is no conflict of interest to be declared.

\section{Authors' contributions:}

All authors contributed to this project and article equally. All authors read and approved the final manuscript. 


\section{References:}

1) Hojat M, Vergare MJ, Maxwell K, Brainard G, Herrine SK, Isenberg GA, et al. The devil is in the third year: a longitudinal study of erosion of empathy in medical school. Academic Medicine. 2009; 84(9): 118291. doi: 10.1097/ACM.0b013e3181b17e55. PMID: 19707055.

2) Shariat SV, Habibi M. Empathy in Iranian medical students: Measurement model of the Jefferson Scale of Empathy. Medical teacher. 2013; 35(1): e913-8.

3) Neumann M, Scheffer C, Tauschel D, Lutz G, Wirtz M, Edelhäuser F. Physician empathy: definition, outcome-relevance and its measurement in patient care and medical education. GMS Z Med Ausbild. 2012; 29(1): 11. doi: 10.3205/zma000781. PMID: 22403596, PMCID: PMC3296095.

4) Dixon D, Sweeney K, Gray D. The physician healer: ancient magic or modern science? Br J Gen Pract. 1999; 49(441): 309-12. PMID: 10736913, PMCID: PMC1313401.

5) Usherwood T. Understanding the consultation: evidence, theory and practice. McGraw-Hill International; 1999.

6) Lewis JR. Patient views on quality care in general practice: literature review. Social science \& medicine. 1994; 39(5): 655-70. doi: 10.1016/0277-9536(94)90022-1.

7) Mercer SW, Reynolds WJ. Empathy and quality of care. Br J Gen Pract. 2002; 52(Suppl): S9-12. doi: 10.1093/fampra/cmh621. PMID: 15528286.

8) Mercer SW, Maxwell M, Heaney D, Watt GC. The consultation and relational empathy (CARE) measure: development and preliminary validation and reliability of an empathy-based consultation process measure. Fam pract. 2004; 21(6): 699-705. doi: 10.1093/fampra/cmh621. PMID: 15528286.

9) Hojat M, Gonnella JS, Mangione S, Nasca TJ, Veloski JJ, Erdmann JB, et al. Empathy in medical students as related to academic performance, clinical competence and gender. Medical education. 2002; 36(6): 5227. doi: 10.1046/j.1365-2923.2002.01234.x. PMID: 12047665.

10) Spiro H, Curnen MGM, Peschel E, James DS. Empathy and the practice of medicine: beyond pills and the scalpel. Yale University Press; 1996.

11) Jha V, Bekker HL, Duffy SR, Roberts TE. A systematic review of studies assessing and facilitating attitudes towards professionalism in medicine. Medical Education. 2007; 41(8): 822-9. doi: 10.1111/j.13652923.2007.02804.x. PMID: 17661891.

12) Hojat M, Louis DZ, Markham FW, Wender R, Rabinowitz C, Gonnella JS. Physicians' empathy and clinical outcomes for diabetic patients. Academic Medicine. 2011; 86(3): 359-64. doi: 10.1097/ACM.0b013e3182086fe1. PMID: 21248604.

13) Del Canale S, Louis DZ, Maio V, Wang X, Rossi G, Hojat M, et al. The relationship between physician empathy and disease complications: an empirical study of primary care physicians and their diabetic patients in Parma, Italy. Academic Medicine. 2012; 87(9): 1243-9. doi: 10.1097/ACM.0b013e3182628fbf. PMID: 22836852.

14) Hojat M. Empathy in patient care: Antecedents, development, measurement, and outcomes. Springer Science \& Business Media; 2007.

15) Hojat M, Vergare M, Isenberg G, Cohen M, Spandorfer J. Underlying construct of empathy, optimism, and burnout in medical students. Int J Med Educ. 2015; 6: 12. doi: 10.5116/ijme.54c3.60cd. PMID: 25633650, PMCID: PMC4332366.

16) Narváez VPD, Palacio LMA. Empathic orientation among medical students from three universities in Barranquilla, Colombia and one university in the Dominican Republic. Arch Argent Pediatr. 2014; 112(1): 41-9.

17) Hojat M, Gonnella JS, Nasca TJ, Mangione S, Veloksi JJ, Magee M. The Jefferson Scale of Physician Empathy: further psychometric data and differences by gender and specialty at item level. Academic Medicine. 2002; 77(10): S58-60.

18) Fernández Pinto I, López Pérez B, Márquez M. Empatía: Medidas, teorías y aplicaciones en revisión. Anales de Psicología. 2008; 24(2).

19) Beckman HB, Frankel RM. The effect of physician behavior on the collection of data. Annals of Internal Medicine. 1984; 101(5): 692-6.

20) Falvo D, Tippy P. Communicating information to patients: patient satisfaction and adherence as associated with resident skill. J Fam Pract. 1988; 26(6): 643-7.

21) Levinson W, Roter DL, Mullooly JP, Dull VT, Frankel RM. Physician-patient communication: the relationship with malpractice claims among primary care physicians and surgeons. JAMA. 1997; 277(7): $553-9$. 
22) Kataoka HU, Koide N, Ochi K, Hojat M, Gonnella JS. Measurement of empathy among Japanese medical students: psychometrics and score differences by gender and level of medical education. Academic Medicine. 2009; 84(9): 1192-7. doi: 10.1097/ACM.0b013e3181b180d4. PMID: 19707056.

23) Rahimi-Madiseh M, Tavakol M, Dennick R, Nasiri J. Empathy in Iranian medical students: a preliminary psychometric analysis and differences by gender and year of medical school. Medical Teacher. 2010; 32(11): e471-8.

24) Morling B, Lamoreaux M. Measuring culture outside the head: A meta-analysis of individualismcollectivism in cultural products. Personality and Social Psychology Review. 2008.

25) Mostafa A, Hoque R, Mostafa M, Rana MM, Mostafa F. Empathy in Undergraduate Medical Students of Bangladesh: Psychometric Analysis and Differences by Gender, Academic Year, and Specialty Preferences. ISRN psychiatry. 2014. doi: 10.1155/2014/375439.

26) Wen D, Ma X, Li H, Liu Z, Xian B, Liu Y. Empathy in Chinese medical students: psychometric characteristics and differences by gender and year of medical education. BMC Med Educ. 2013; 13: 130. doi: 10.1186/1472-6920-13-130. PMID: 24053330, PMCID: PMC3848862.

27) Hojat M, Gonnella JS, Nasca TJ, Mangione S, Vergare M, Magee M. Physician empathy: definition, components, measurement, and relationship to gender and specialty. Am J Psychiatry. 2002; 159(9): 1563 9. PMID: 12202278.

28) Preusche I, Lamm C. Reflections on empathy in medical education: What can we learn from social neurosciences? Adv Health Sci Educ Theory Pract. 2016; 21(1): 235-49. doi: 10.1007/s10459-015-9581-5. PMID: 25597025.

29) Paro HB, Silveira PS, Perotta B, Gannam S, Enns SC, Giaxa RR, et al. Empathy among medical students: is there a relation with quality of life and burnout? PloS One. 2014; 9(4): e94133. doi: 10.1371/journal.pone.0094133. PMID: 24705887, PMCID: PMC3976378.

30) Khademalhosseini M, Khademalhosseini Z, Mahmoodian F. Comparison of empathy score among medical students in both basic and clinical levels. J Adv Med Educ Prof. 2014; 2(2): 88-91. PMID: 25512926, PMCID: PMC4235551.

31) Sherman JJ, Cramer A. Measurement of changes in empathy during dental school. J Dent Educ. 2005; 69(3): 338-45. PMID: 15749944.

32) Vallabh K. Psychometrics of the student version of the Jefferson Scale of Physician Empathy (JSPE-S) in final-year medical students in Johannesburg in 2008. South African Journal of Bioethics and Law. 2011; 4(2): 63-8.

33) van Ryn M, Hardeman RR, Phelan SM, Burke SE, Przedworski J, Allen ML, et al. Psychosocial predictors of attitudes toward physician empathy in clinical encounters among 47321 st year medical students: A report from the CHANGES study. Patient education and counseling. 2014; 96(3): 367-75. doi: 10.1016/j.pec.2014.06.009. PMID: 25065328, PMCID: PMC4195739.

34) Prabhu S, Kumar V, Prasanth S, Kishore S. Standing in patients' shoes - survey on empathy among dental students in India. Journal of Education and Ethics in Dentistry. 2014; 4(2): 69. doi: 10.4103/09747761.148990 .

35) Roh MS, Hahm BJ, Lee DH, Suh DH. Evaluation of empathy among Korean medical students: a crosssectional study using the Korean Version of the Jefferson Scale of Physician Empathy. Teaching and learning in medicine. 2010; 22(3): 167-71. doi: 10.1080/10401334.2010.488191. PMID: 20563934.

36) Magalhães E, Salgueira AP, Costa P, Costa MJ. Empathy in senior year and first year medical students: a cross-sectional study. BMC Med Educ. 2011; 11(1): 52, doi: 10.1186/1472-6920-11-52. PMID: 21801365, PMCID: PMC3163625.

37) Hojat M, Mangione S, Nasca TJ, Rattner S, Erdmann JB, Gonnella JS, et al. An empirical study of decline in empathy in medical school. Med Educ. 2004; 38(9): 934-41. doi: 10.1111/j.1365-2929.2004.01911.x. PMID: 15327674.

38) Chen D, Lew R, Hershman W, Orlander J. A cross-sectional measurement of medical student empathy. Journal of General Internal Medicine. 2007; 22(10): 1434-8. doi: 10.1007/s11606-007-0298-x. PMID: 17653807, PMCID: PMC2305857.

39) Allen $D$, Wainwright M, Mount $B$, Hutchinson T. The wounding path to becoming healers: medical students' apprenticeship experiences. Med Teach. 2008; 30(3): 260-4. doi: 10.1080/01421590701758665. PMID: 18484452.

40) Bellini LM, Shea JA. Mood change and empathy decline persist during three years of internal medicine training. Acad Med. 2005; 80(2): 164-7. doi: 10.1097/00001888-200502000-00013. PMID: 15671323. 